\title{
A IMAGEM DOS PRAÇAS NA FORMAÇÃO DO EXÉRCITO BRASILEIRO (1864-1945)
}

\author{
The image of soldiers in the formation \\ of the Brazilian Army
}

\author{
Bruno Torquato Silva Ferreira* \\ Marcos Hanemann**
}

BEATTIE, Peter M. Tributo de sangue: exército, honra, raça e nação no Brasil (1864-1945). Tradução de Fábio Duarte Joly. São Paulo: Editora da Universidade de São Paulo, 2009.

Peter M. Beattie pertence a uma nova safra de historiadores brasilianistas pouco publicados no Brasil. Além de um capítulo da Nova História Militar, editada pela Fundação Getúlio Vargas, ${ }^{1}$ e alguns textos de conferências realizadas em Pernambuco, Santa Catarina e no Rio de Janeiro, toda sua obra estava restrita aos leitores de língua inglesa. Finalmente a Edusp decidiu traduzir sua única obra individual e possibilitar aos lusófonos conhecerem algumas questões tratadas com singularidade por Beattie, como a sexualidade, o machismo, a honra masculina e a identidade nacional, sempre no contexto da transição do escravismo para o trabalho livre no Brasil. ${ }^{2}$

Tributo de sangue desenvolve a maneira pela qual ocorreu a transição do recrutamento forçado para a conscrição através de sorteio ${ }^{3}$

* Doutorando em História UFPR

"* Doutorando em História, USP.

1 "Ser homem pobre, livre, e honrado: a sodomia e as praças nas forças armadas brasileiras, 1860-1930". In: CASTRO, C.; IZECKSOHN, V.; KRAAY, H. (Org.). Nova História Militar Brasileira. Rio de Janeiro: FGV, 2004.

2 Extraído do sítio <http://families.msu.edu/vitas/pbeattie.pdf > . Acesso em: 07/02/2012, às 21:05 (horário de Brasília).

3 O sorteio militar foi a técnica estabelecida pelo Governo Central para a aplicação do princípio do serviço militar obrigatório no Brasil. Houve duas leis instituindo o sorteio militar: a primeira durante o Império (em 1874) e a segunda durante a República (em 1908). Sua aprovação gerou muita resistência passiva e ativa à sua aplicação nos dois casos, mas finalmente "pegou" a partir de 1916 e funcionou até 1945, quando nova lei estabeleceu a obrigatoriedade de os jovens, no ano do seu aniversário de 18 anos, se apresentarem às juntas do serviço militar do município de sua residência. 
como forma de preenchimento dos claros (vazios) das fileiras do Exército brasileiro entre 1864 e 1945 . O corte é pouco usual para os que acompanham os estudos nativos sobre o tema e refere-se às duas mais importantes mobilizações militares que o Brasil conheceu: a guerra contra o Paraguai e a Segunda Guerra Mundial. Coincide ainda com importantes alterações nas estruturas social, econômica e política brasileiras, que se materializaram na expansão das atividades capitalistas, no processo de urbanização, na industrialização, na expansão do sistema viário, na integração nacional, no avanço do nacionalismo e no aumento do poder do Estado.

Pode-se afirmar, portanto, que o corte cronológico também revela o objetivo de demonstrar a relação direta entre o processo de consolidação do Estado brasileiro - que teve como corolário o aumento do papel monopolizador da violência pelo Exército (p. 38) - e a profissionalização do Exército, pois essa nova modalidade de recrutamento acarretou uma alteração significativa do perfil do soldado médio e "mudou a carreira e status do soldado raso". Com o sorteio, o "convocado substituía o mais picaresco soldado do infortúnio como fonte de mão de obra do Exército". Essa instituição adquiriu, nos planos retórico e prático, uma perspectiva reformadora, a qual implicou o abandono do perfil punitivo (p. 29). O Exército brasileiro tornou-se ainda mais atraente às pessoas de origens sociais "modestas" interessadas em prosseguir seus estudos (p. 69-70).

Depreende-se daí que o foco central do livro consiste em explicar como as atitudes diante do serviço militar começaram a mudar no início do século XX (p. 191), principalmente no que se refere às mudanças ocorridas nas relações entre o Estado e as camadas pobres livres no período considerado (p. 38). Ao aprofundar-se nesse aspecto, Beattie dá vazão às suas tendências culturalistas. Enfatizando a analogia soldado/escravo, ${ }^{4}$ afirma que as deserções, assim como as fugas dos escravos do cativeiro, tinham um simbolismo muito caro aos soldados: libertar-se da opressão nas casernas era ao mesmo tempo uma afirmação de masculinidade (p. 27). A esse respeito, notou nas charges da imprensa um maior espaço dedicado à

4 Observe-se, como Beattie apontou que o Exército aplicava castigos corporais, em público, aos soldados desobedientes. Prática que mantinha os praças "desconfortavelmente perto da condição de escravos "desonrados". Os quartéis segregavam os praças da sociedade que os rodeava de maneira muito semelhante aos presídios e às senzalas (p. 34). 
ridicularização dos soldados e dos que lucravam com o recrutamento do que à vilificação dos evasores (p. 84).

Para alcançar as representações em torno das concepções populares do serviço militar na condição de praça, Beattie lança mão de versos, poesias, modinhas e outros recursos literários. Em seu entendimento, o uso da literatura e de outros fragmentos que revelam aspectos da chamada cultura popular constituem estratégias para perscrutar as relações sociais e o imaginário em torno das concepções em torno do serviço militar (p. 27). Um dos aspectos mais notáveis dessa proposta foi a análise da obra poética e da experiência de vida do mulato Domingo Caldas Barbosa, de quem usou os versos para "explorar o pouco estudado mundo dos pobres livres no Brasil e sua interação com o Estado entre 1864 e 1945" (p. 23), muito embora tenha sido um poeta do século XVIII. Essa incoerência cronológica não se configura um problema metodológico se nos ativermos à proposta apresentada de interpretar a relação dos homens livres e pobres com o serviço militar como um fenômeno de longa duração na sociedade brasileira.

Apoiado nessa visão popular da caserna, Beattie descreve os quartéis da segunda metade do século XIX e dos anos iniciais do século XX como "o equivalente masculino dos bordéis", pois "ambos objetivavam afastar homens 'perigosos' e mulheres 'solitárias' das casas de família 'honradas" (p. 34). De fato, o Exército desse período era o lugar para onde os agentes do Governo enviavam os detidos, os inconformistas, os vadios e os suspeitos. Por essa razão, é possível concluir que o recrutamento permaneceu forçado, em alguma medida e provavelmente decrescente, por todo o período que precedeu o estabelecimento do sorteio militar no Brasil (p. 26). Ao final do período em apreciação, o quadro era totalmente diferente: redução drástica da criminalidade no interior dos quartéis, melhoria da imagem pública do Exército e dos soldados, efetivos maiores, introdução de métodos modernos de treinamento e, finalmente, os quartéis passam a ser vistos como locais honrados (p. 28-29).

Ao analisar a "luta do Estado para reformar" o sistema de recrutamento (p. 29), sua investigação esbarrou nas relações dos "brasileiros pobres" com o clientelismo, que os dividia em duas categorias: os protegidos (aqueles com patrono preeminente) e os desprotegidos (os sem patrono) (p. 18). Ao deparar-se com essas duas categorias, Beattie optou pelo instrumental weberiano para compreender a expansão e transformação 
da burocracia militar brasileira; isto porque trata da, por assim dizer, queda de braço institucional entre a estrutura de poder legal (imbuída de valores como a impessoalidade, eficiência e precisão) e a estrutura tradicional de autoridade (marcada pelo personalismo, clientelismo e por princípios de privilégio). ${ }^{5}$ Reconhecendo no Exército um braço da burocracia impessoal do Império, percebeu que "muitos coronéis temiam que um Exército forte pudesse cercear sua autonomia; portanto, opunham-se a qualquer reforma significativa do Exército." (p. 64).

Por um lado, o sorteio militar era um meio economicamente barato de manter as fileiras preenchidas e diminuir o tempo de serviço militar; por outro lado, era uma inovação custosa em termos sociais e culturais, pois sua aplicação desafiava os valores brasileiros tradicionais (p. 131). Aplicar o sorteio "significava superar uma variedade de barreiras culturais, políticas e institucionais", já que, até então, os "criminosos formavam o grosso da mais poderosa instituição estatal responsável por administrar a violência pública" (p. 132).

Em outras palavras, e voltando a uma temática cara à historiografia, tratou-se de investigar um aspecto da modernização da sociedade brasileira e sua convivência, até certo ponto ambivalente, com o coronelismo, manifestação do poder privado e local no Brasil. Nesse aspecto, as referências a Roberto da Mata vêm ao encontro da hipótese geral de pesquisa, pois, segundo Beattie, os "brasileiros associam casa com honra, ordem, casamento, segurança, família e poder privado, enquanto a rua implica infortúnio, caos, ilegalidade, perigo, mendicância e vulnerabilidade aos caprichos da autoridade pública impessoal" (p. 32), tratando-se, portanto, de um dado cultural de longa duração. ${ }^{6}$ Desse modo, procurou analisar os "fatores [que] impediram a realização de um sorteio baseado no ideal de igualdade da conscrição masculina universal" (p. 29), atentando para os "protestos populares, [as] rivalidades entre partidos políticos, [a] falta de infraestrutura, [a] intransigência burocrática, [as] disputas regionais, [os] privilégios patriarcais, [as]

5 Abordagem semelhante pode ser observada em MENDES, Fábio Faria. A economia moral do recrutamento no Império Brasileiro. Revista Brasileira de Ciências Sociais, São Paulo, v. 13, n. 38, out. 1998, no tocante às tentativas de aplicação da Lei n ${ }^{\circ} 2.556$ de 1874 durante o Império.

6 Mesmo assim, a concepção foi criticada pelo autor: "Algumas das rígidas distinções traçadas por da Matta entre casa e rua, como esferas separadas de relações sociais 'pessoais' versus relações 'individualistas', tornaram-se problemáticas quando se busca explicar as mudanças ao longo do tempo" (p. 32). 
ideologias e o papel do exército na justiça penal” (p. 29), mesmo após 1916, quando o sorteio militar passou a alcançar um sucesso relativo.

O desafio do Estado estava em modificar uma característica secular do Exército brasileiro: a finalidade protopenal dos quartéis. Essa luta institucional era travada ao mesmo tempo em que uma luta simbólica, e não menos importante, se afigurava: pela mudança do status dos soldados. As duras condições de trabalho, o recrutamento forçado, o regime disciplinar, a remuneração, as denúncias de práticas sodomitas nos quartéis, entre outros fatores, conspiravam para uma visão deletéria da vida do soldado. ${ }^{7}$ Ressalte-se que o tema do combate à sodomia foi explorado pelo autor como um aspecto da luta travada pelos militares para melhorar a imagem do serviço militar na condição de praça nas Forças Armadas brasileiras (p. 299-305). ${ }^{8}$

Via de regra, os soldados eram vistos como degenerados, criminosos, doentes, desajustados e irrecuperáveis sociais: "Se o lar familiar heterossexual representava, em um extremo, os valores da sociedade, os quartéis situavam-se no extremo oposto" (p. 33). Há aqui uma grande contradição do Estado, pois armava e, ainda que rudimentarmente, treinava, visando garantir a ordem interna, indivíduos que ele próprio marginalizava. O próprio autor reconhece que "o debate sobre a conscrição tocava em uma miríade de questões: escravidão, trabalho livre, relações entre Igreja e Estado, penologia, fraude eleitoral e direitos de família, entre outras" (p. 115).

Caberia, portanto, ao Exército afastar os quartéis do mundo da rua, tornando-os uma extensão do próprio lar do conscrito (p. 33). Daí a ideia do Exército como uma família, professada pelos defensores do princípio da nação em armas. Nesse sentido, o termo "praça", que designa a situação do conscrito, "deriva do termo praça pública ou, mais provavelmente, de 'praça de armas' (local destinado a exercícios militares)", termo que linguisticamente localizava "os soldados no mundo arruaceiro e libertino da rua" (p. 33). Urgia livrar as fileiras de indivíduos dessa qualidade.

7 Contudo, vale reconhecer que o autor pontua que o Exército aparecia para muitos como opção, dado o fato de que, no Brasil da época, "muitos pequenos proprietários, colonos, trabalhadores agrícolas, vadios, escravos e migrantes urbanos viviam em condições ainda mais duras" que as dos soldados. Com efeito, para alguns "a vida no exército representava uma melhora em suas condições: muitos voluntários alistavam-se para escapar da fome, desemprego, falta de moradia e, às vezes, da escravidão" (p. 28).

8 Beattie tratou do assunto no já mencionado capítulo "Ser homem pobre, livre, e honrado: a sodomia e as praças nas forças armadas brasileiras, 1860-1930”. In: CASTRO, C.; IZECKSOHN, V.; KRAAY, H. (Org.). Nova História Militar Brasileira. Rio de Janeiro: FGV, 2004. 
Um dos pontos mais louváveis de Tributo de sangue é a cautela do autor no que se refere ao uso indiscriminado do termo voluntário para se referir aos indivíduos alistados antes da década de 1910, pois o recrutamento forçado era ilegal conquanto persistisse uma prática rotineira ( $\mathrm{p}$. 83). É notável o zelo conceitual com que é analisada a diferença entre recrutamento forçado e conscrição, revelando que o embaralhamento entre os dois conceitos assemelha-se à equiparação entre a servidão por contrato e a escravidão: "Tanto a conscrição como o recrutamento forçado são, em última instância, formas de trabalho compulsório, mas seus métodos e os significados atribuídos a eles são distintos". Conscrição significa "alistar ou selecionar de uma lista" e refere-se "à obrigação dos cidadãos romanos da República (homens que satisfaziam os requisitos mínimos de propriedade) de se alistarem como adultos capacitados a serem periodicamente convocados para o serviço militar" (p. 83).

Por outro lado, recrutamento forçado "descreve um ato coercitivo realizado na maioria dos casos pela determinação de membros de polícia ou por agentes de recrutamento que apanhavam homens 'recrutáveis' nas ruas". Os alvos desses últimos eram cidadãos sem propriedade, desocupados, marginais e criminosos. A conscrição era dirigida a um perfil de jovem totalmente oposto: indivíduos não fichados criminalmente, de "boa saúde", moral considerada "saudável" e preferencialmente alfabetizados (p. 19). A constatação de que o serviço militar é um regime de trabalho semicoercitivo, ${ }^{9}$ óbvia à primeira vista, ainda não teve até o momento a repercussão merecida na historiografia brasileira.

Já o tema da masculinidade ocupa importante espaço na explicação da difusão, principalmente entre os setores letrados da população, do arquétipo da virilidade, característica dos países europeus da Belle Époque e que no Brasil ganhou ênfase durante e após a Primeira Guerra Mundial. As noções de modernidade e civilização eram associadas ao modo de vida percebido como europeu por esta camada da sociedade. O serviço militar obrigatório, nesse sentido, sendo uma inovação originária de países europeus, consubstanciava-se num dos critérios para o ingresso da nação brasileira no grêmio dos países civilizados (p. 125-126).

9 Este ponto já havia sido assinalado por Frank McCann no seu Soldados da Pátria: História do Exército Brasileiro. 
Ainda que em menor escala, o enfoque da masculinidade também foi empregado para um trabalho gradual de convencimento entre os setores médios e inferiores da sociedade de que o serviço militar era algo digno e enobrecedor ao indivíduo. Foi uma decorrência da constatação, como observa Beattie, de que o trabalho de persuasão deveria envolver uma luta pelo domínio da "geografia simbólica e retórica da honra e masculinidade", sendo a substituição do artigo definido feminino $a$ pelo artigo definido masculino $o$ antes do termo praça ao se referir aos soldados um "indicador revelador [de que] desse esforço consciente começou a aparecer no começo do século XX" (p. 406-407). ${ }^{10}$

De fato, procuravam instilar a noção de que a virtude masculina adviria do serviço público, de sentimentos e atitudes como o patriotismo, coragem, estoicismo, abnegação, esportividade, belicismo (p. 189). Neste particular, organizações como as linhas de tiro desempenharam um papel essencial na propagação desses valores cívicos, ${ }^{11}$ contribuindo para eclipsar a noção tradicional de virilidade que motivava importantes parcelas da população a evadir-se das obrigações militares. Com efeito, os defensores do serviço militar obrigatório esforçavam-se por adjetivar os jovens conscritos com atributos enaltecedores em que se destacavam as noções de defesa e honra nacional como uma missão sagrada e os seus defensores como sacerdotes, celibatários e estoicos. Explicavam, ainda, que o sorteio e a disciplina militar fortaleceriam os valores familiares, a ética do trabalho e as virtudes masculinas (p. 340). ${ }^{12}$

A noção de honra masculina incorporava agora a percepção de que "os homens da casa defendessem seus parentes, dependentes, além de si próprios, contra agressões sexuais e outros homens". A pátria passou corporificar o lar que todos os homens sãos deveriam defender. A intelectualidade imbuída (falsa ou verdadeiramente) do espírito de nacionalidade procurava relacionar a violação da pátria a um grave insulto que deveria ser evitado a todo custo (p. 33). O Exército passou a ser idealizado como

10 Para muitos, o Exército também aparecia como instituição talhada para a melhoria da raça brasileira (p. 190).

11 Linhas de Tiro eram organizações destinadas a formar atiradores aptos a atuarem nas reservas do Exército em caso de guerra. Em geral, os instrutores eram militares do Exército (oficiais ou praças) e a declaração de aptidão nas linhas de tiro dispensava os seus possuidores do serviço militar ordinário.

12 Vale observar que, no plano retórico, a virtude militar se confunde com a honra masculina e que o autor rastreia metáforas que implicam a derrota militar à violência sexual contra as mulheres dos povos derrotados (p. 403). 
o povo fardado e houve uma crescente atuação do Estado na regulação dos espaços privados com finalidades disciplinadoras (p. 33). Com o tempo parece ter ganhado força a percepção do Exército como instrumento de "reforma social" (p. 217).

Mas nem só de méritos é construído o Tributo de Sangue. Embora toda a obra seja bem fundamentada, há dois momentos em que Beattie faz afirmações contundentes sem referenciar suas fontes. A primeira aparece na p. 200, na qual, com alguma dose de exagero, ele afirma que os oficiais "escolhiam recrutas em público, em cenas que lembravam um mercado de escravos". Não estão descritas no livro fontes que permitam essa inferência. Além disso, na p. 207, Beattie conclui a partir de "fontes quantitativas e qualitativas" que "um dentre dois alistados, de 1870 a 1883 , tinha sido coagido ao serviço, ao contrário das estatísticas oficiais que sustentam que isso acontecia para um dentre três alistados." No entanto, não demonstrou como chegou a essa estimativa e antes, na p. 174, havia admitido a ausência de elementos empíricos para demonstrar o funcionamento do recrutamento forçado.

No fim do percurso do livro, a trajetória descrita pelo Exército entre a segunda metade do século XIX e a primeira do XX aparece ao leitor como a transformação de uma instituição penal em uma instituição preventiva e voltada para a reforma social. Sinal dos tempos, o Exército - na condição de elemento central do aparato monopolizador da violência em âmbito nacional - seria agora o principal vetor do aperfeiçoamento do homem brasileiro. Também se modificou a relação do "homem pobre" com o Exército; essa modificação, conforme o rastreamento apresentado pelo autor, foi ensejada por uma reorientação dos elementos discursivos a serviço das causas nacionalistas, que confluiu - para além das necessidades defensivas da nação e disciplinares no interior dos quartéis - num consenso em torno da constatação da necessidade do serviço militar obrigatório com vistas ao atendimento das demandas eugenistas. Nesse ínterim, princípios como o da regeneração nacional através da educação marcial da juventude masculina e a tendência geral à universalização do nacionalismo brasileiro contribuíram para o enfraquecimento dos ideais de hierarquias raciais, sociais e de gênero tradicionais, reflexo, possivelmente, das alterações estruturais vivenciadas pela sociedade brasileira no período apreciado pela obra.

É interessante observar que, em sua leitura do processo que redundou na vigência do sorteio militar, Beattie enfatizou a correlação interna de 
forças em detrimento dos imperativos internacionais (disputas geopolíticas com a Argentina, por exemplo). O funcionamento do sorteio implicava múltiplas confrontações estruturais: I) contra as autoridades tradicionais; II) contra os valores tradicionais; III) contra os particularismos locais; IV) contra as dificuldades internas de transportes e comunicações; V) contra os próprios entraves das estruturas burocráticas; VI) contra as ideias anarquistas do movimento operário; VII) contra os liberais; VIII) enfim, contra a percepção negativa do serviço militar na condição de praça. Acompanhando a corrente geral de pensamento que orienta os estudos sobre a atuação política do Exército no século XX - iniciada com os estudos de José Murilo de Carvalho, Edmundo Campos Coelho, Frank McCann, dentre outros - acentua, portanto, a luta da burocracia militar contra as resistências internas. Acima de tudo, parecia estar em jogo a imposição de uma determinada visão de ordem, de civilização, de modernidade e de nacionalidade emanada dos centros de decisão brasileiros.

Resta questionar o que há de particular e o que há de genérico na trajetória brasileira no que se refere ao serviço militar. É certo que o número reduzido de guerras externas ou mesmo de ameaças externas de vulto ${ }^{13}$ contribuiu amplamente para moldar uma cultura militar gendarme no Brasil: policialesca e voltada para dentro (o chamado imperialismo interno).

Entretanto, essas observações têm muita consistência a ganhar se os pesquisadores se dispuserem a contemplar em suas análises a convivência das diversas sociedades com o serviço militar obrigatório. De fato, Peter Beattie nos convida a essa reflexão ao sinalizar para uma cultura militar transatlântica. Nesse sentido, estaríamos diante de uma proposta de história comparada bastante alvissareira: o exame da construção do Estado na Europa e nas Américas sob o prisma da conscrição militar.

Recebido em março de 2012. Aprovado em abril de 2013.

13 Afinal, como demonstrou Demétrio Magnoli em seu O corpo da Pátria, os últimos conflitos diplomáticos com a Argentina em torno das questões de limites foram resolvidos nos anos iniciais da República, durante a gestão do Barão do Rio Branco no Ministério das Relações Exteriores (1902-1912). 